\title{
Changes in mesolimbic dopamine may explain stress-induced anhedonia
}

\author{
PAUL WILLNER \\ City of London Polytechnic, London, England \\ KRYSTYNA GOLEMBIOWSKA and VIOLETTA KLIMEK \\ Polish Academy of Sciences, Krakow, Poland \\ and \\ RICHARD MUSCAT \\ City of London Polytechnic, London, England
}

\begin{abstract}
The mesolimbic dopamine projection to the limbic forebrain is known to be critically involved in responsiveness to rewards. In two experiments, the consumption of palatable weak sucrose solutions by rats was reduced by chronic exposure to mild unpredictable stress. Increases in the levels of dopamine and serotonin and their metabolites were found in the limbic forebrain of stressed rats; these changes were not present in the caudate nucleus or septal area, or in the brains of meal-fed control animals. In the first experiment (7 weeks of stress), specific binding to dopamine D2 receptors was decreased in limbic forebrain; this change was not seen in the second experiment ( 3 weeks of stress). We discuss the possible role of these changes in mesolimbic dopamine function in the reduced sensitivity to reward that follows exposure to chronic mild stress.
\end{abstract}

One of the most intriguing effects of stress is a subsequent decrease in the performance of rewarded behavior. This effect has typically been observed following acute exposure to electric shock (Anderson, Cole, \& McVaugh, 1968; De Cola, Rosellini, \& Warren, 1988; Rosellini, 1978; Rosellini \& De Cola, 1981; Rosellini, De Cola, Plonsky, Warren, \& Stillman, 1984; Zacharko \& Anisman, 1991; Zacharko, Bowers, \& Anisman, 1984; Zacharko, Bowers, Kokkinidis, \& Anisman, 1983) or chronic exposure to a variety of severe stressors (Katz, 1982). We have recently reported that rewarded behavior is also depressed by chronic mild stress (Muscat, Sampson, \& Willner, 1990; Muscat, Towell, \& Willner, 1988; Sampson, Muscat, \& Willner, in press; Willner, Muscat, Papp, \& Sampson, 1991; Willner, Towell, Sampson, Sophokleous, \& Muscat, 1987).

There are good reasons for believing that the mesolimbic dopamine (DA) system might mediate these effects. The mesolimbic system is known to be activated by rewards (Heffner, Hartman, \& Seiden, 1980; Hernandez \& Hoebel, 1988; Phillips, Blaha, \& Fibiger, 1989), and such activity is crucial for the reinforcing effects of diverse classes of reward, including brain stimulation reward, drug rewards, and food (Hoebel et al., 1981; Wise,

This study was supported in part by the Medical Research Council of Great Britain. We gratefully acknowledge the assistance of Gavin Phillips, Mariusz Papp, David Sampson, and Glen Freary in the conduct of the experiments, and thank Professor J. Maj for providing facilities to carry out the biochemical analyses. Correspondence may be addressed to Paul Willner, Department of Psychology, City of London Polytechnic, Old Castle St., London E1 7NT, England.
1982; Wise \& Bozarth, 1984). Uncontrollable electric shock has been found to suppress behavior reinforced by stimulation of the ventral tegmental area (the area of origin of the mesolimbic DA system), while not affecting responding for stimulation in the substantia nigra (Zacharko et al., 1984; Zacharko et al., 1983). We now present evidence of neurochemical changes within the mesolimbic DA system, in rats subjected to chronic mild unpredictable stress.

\section{METHOD}

\section{Subjects}

Male hooded Lister rats were obtained from the National Institute for Medical Research (U.K.). The animals were singly housed, except where grouped as part of the stress procedure (see below). All procedures were approved by the U.K. Home Office under Project License PPL 70/00985.

\section{Procedure}

Experiment 1. Three groups of rats $(n s=10)$, which were first trained to consume a palatable weak $(0.7 \%)$ sucrose solution, were used in this experiment. One group was subjected to chronic unpredictable mild stress for a total of 7 weeks; a variety of mild stressors were used, each for a period of between 0.5 and $20 \mathrm{~h}$. During Weeks 1-5, stressors could occur at any time of day; during Weeks 6 and 7, stressors were administered at night only, in order not to impinge directly on daily sucrose intake tests (see below). The stress regime used in each of Weeks 1-5 was similar to that used previously (Muscat et al., 1990; Muscat et al., 1988; Sampson et al., in press; Willner et al., 1987). It consisted of two 20-h periods of food and water deprivation, one immediately prior to the sucrose intake test, the other followed by $2 \mathrm{~h}$ of restricted access to food (scattering of a few $45-\mathrm{mg}$ precision pellets in the cage); one additional 16-h period of water deprivation, followed 
by a 1-h exposure to an empty bottle; two periods of continuous overnight illumination; two periods ( 7 and $17 \mathrm{~h}$ ) of $45^{\circ}$ cage tilt; one 17-h period of grouped housing; one 17-h period in a soiled cage $(100 \mathrm{ml}$ water in sawdust bedding); two periods ( 3 and $5 \mathrm{~h}$ ) of intermittent white noise $(85 \mathrm{~dB})$; three periods $(7,9$, and $17 \mathrm{~h}$ ) of low intensity stroboscopic illumination ( 100 flashes/min). During Weeks 6-7, the stress regime consisted of overnight exposures to continuous illumination (twice); soiled cage; white noise; grouped housing; stroboscopic illumination; cage tilt. A control group was deprived of food and water for $20 \mathrm{~h}$ preceding each sucrose intake test; otherwise, this group had free access to food and water. The third group of animals was included to control for effects of the stress regime on body weight; these animals were fed between 1800 and $1900 \mathrm{~h}$ daily, but they were not otherwise stressed (and had free access to water). Initial weights were around $320 \mathrm{~g}$. During Weeks 1-5, controls gained $15 \mathrm{~g}$; stressed animals lost $7 \mathrm{~g}$; mealfed animals lost $31 \mathrm{~g}$.

Beginning 1 week before the onset of stress, and throughout the experiment, all animals were allowed access to $0.7 \%$ sucrose for $1 \mathrm{~h}$ weekly; these tests took place on Tuesdays at $1400 \mathrm{~h}$, in the home cage, following $20 \mathrm{~h}$ of food and water deprivation. Sucrose consumption was measured by weighing preweighed bottles. In addition, consumption of stronger sucrose solutions $(2.1 \%, 7 \%, 13.6 \%$, and $34 \%$ ) was tested on the Wednesday through Saturday of the week prior to stress onset, and again during Weeks 6 and 7 of stress.

Experiment 2. Two groups of rats ( $n=10$ per group), one of which was exposed to the chronic mild stress regime, were used in Experiment 2. The experiment was terminated after only 3 weeks of stress, but it was in other respects identical to Experiment 1 .

\section{Neurochemical Analyses}

Following the final fluid consumption test, stress and food deprivation were terminated. The animals were killed by stunning and decapitation 46-48 h later. Their brains were rapidly removed, and the caudate nucleus, limbic forebrain (primarily nucleus accumbens and olfactory tubercle), and septal area (Experiment 2 only) were dissected out over ice; samples were dissected from a slice obtained by cuts perpendicular to the ventral surface of the brain at the anterior and posterior extremities of the olfactory tubercle. Samples of limbic forebrain (both experiments) and caudate nucleus (Experiment 1 only) were coarsely chopped and then divided into two subsamples, for analysis of monoamine and metabolite levels, and DA receptor binding characteristics, respectively. The samples were stored at $-80^{\circ} \mathrm{C}$, except for a $12-\mathrm{h}$ period in dry ice, during which time they were transported between the two laboratories.

For analysis of monoamine and metabolite levels (all samples), tissues were homogenized in 10 volumes of ice-cold $0.1-\mathrm{M}$ trichloroacetic acid containing $0.05-\mathrm{mM}$ ascorbic acid. After centrifugation at $10,000 \mathrm{~g}$ for $5 \mathrm{~min}$, the supernatents were filtered through RC-58 $0.2-\mu \mathrm{m}$ membranes (Bioanalytic Systems, West Lafayette, IN) and transmitter/metabolite levels were determined by high-performance liquid chromatography (HPLC) with electrochemical detection. A BAS-400 liquid chromatograph was equipped with a $7-\mu \mathrm{m}$ ODS guard column and a $3-\mu \mathrm{m}$ Phase-2 ODS cartridge column $(100 \times 3.2 \mathrm{~mm})$. The mobile phase consisted of $0.05-\mathrm{M}$ citrate-phosphate buffer (pH 3.5), 0.1-mM EDTA, 1-mM sodium octyl sulfonate, and 3.5\% methanol. The applied voltage was set at $0.8 \mathrm{~V}$ versus an $\mathrm{Ag} / \mathrm{AgCl}$ electrode, and the flow rate was maintained at $0.8 \mathrm{ml} / \mathrm{min}$. Concentrations were determined by peak height comparisons with standards run on the day of analysis.

Specific binding of ${ }^{3} \mathrm{H}$-spiperone (NEN, specific activity $40 \mathrm{Ci} / \mathrm{mmol}$ ) and ${ }^{3} \mathrm{H}-\mathrm{SCH}-23390$ (Amersham, specific activity $74.8 \mathrm{Ci} / \mathrm{mmol}$ ) was measured in eight limbic forebrain samples from each group. Each sample was homogenized in 100 volumes of an ice-cold potassium phosphate buffer ( $50 \mathrm{mM}, \mathrm{pH} 7.4)$, using a Polytron homogenizer. The homogenates were centrifuged at $25,000 \mathrm{~g}$ for $10 \mathrm{~min}$; the pellets were rehomogenized and recentrifuged. The final pellets were resuspended in the buffer in a volume corresponding to $2.5 \mathrm{mg}$ (limbic forebrain) or $1 \mathrm{mg} / \mathrm{kg}$ (caudate nucleus) of original tissue per milliliter. Specific binding was assessed as described by Klimek and Nielsen (1987), using a single concentration of each ligand (0.3 nM). In Experiment 1, Scatchard analysis of D2 receptor binding was also carried out, using ${ }^{3} \mathrm{H}$-spiperone concentrations ranging from 0.01 to $1.5 \mathrm{nM}$, as previously described (Klimek \& Nielsen, 1987). Pooled tissues were analyzed (in duplicate) from the remaining two limbic forebrain samples in each group, and from three pairs of caudate nucleus samples in each group. Two further assays were carried out to determine D2 receptor agonist affinity, assessed by the displacement of ${ }^{3} \mathrm{H}$-spiperone, using 10 concentrations of quinpirole between $10^{-8}$ and $10^{-3} \mathrm{M}$, as described by Klimek and Maj (1990). In each of these assays, the pooled residues from four of the limbic forebrain samples were used.

\section{Statistical Analysis}

The results were analyzed by analysis of variance, supplemented where appropriate by tests of simple main effects and planned comparisons. For the HPLC data, each compound was analyzed separately, using two-way analysis of variance (treatment $\times$ brain area), with the exception of NA (noradrenaline), for which oneway analyses were used on account of inhomogeneity of variance between the two brain regions (limbic forebrain/caudate nucleus). In Experiment 2, 4 of the 10 septal samples were lost in the stressed group; these data were therefore analyzed separately from the main analysis of variance.

\section{RESULTS}

\section{Sucrose Consumption}

In both experiments, consumption of $0.7 \%$ sucrose fell drastically in the stressed animals. The results of Experiment 1 are shown in Figure 1 [treatment $x$ weeks interaction: $F(14,189)=6.2, p<.001]$. In Experiment 2, sucrose consumption after 3 weeks of stress had fallen to $73 \%$ of control $[F(1,18)=12.1, p<.001$; results not shown]. As in previous studies (Muscat \& Willner, 1989; Towell, Muscat, \& Willner, 1987), testing with

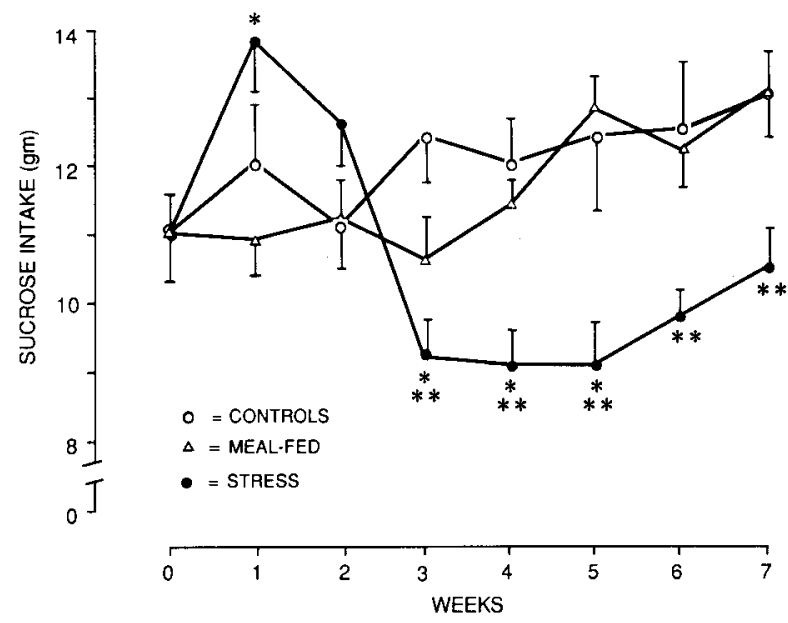

Figure 1. Mean intake $( \pm S E$ ) of $0.7 \%$ sucrose, measured in 1-h weekly tests. Stress slightly increased intake at Week 1 , but greatly decreased sucrose intake from Week 3 onwards. The intake of mealfed animals did not differ from that of controls. ${ }^{*} p<.05$, ${ }^{* * p}<.01, * * * p<.001$. 
Table 1

Transmitter and Metabolite Concentrations

\begin{tabular}{|c|c|c|c|c|c|c|}
\hline & \multicolumn{3}{|c|}{ Limbic Forebrain } & \multicolumn{3}{|c|}{ Caudate Nucleus } \\
\hline & Control & Meal-Fed & Stress & Control & Meal-Fed & Stress \\
\hline $\begin{array}{l}\text { DA } \\
\text { DOPAC } \\
\text { HVA } \\
\text { 3-MT }\end{array}$ & $\begin{array}{c}2,843 \pm 446 \\
750 \pm 129 \\
150 \pm 26 \\
69 \pm 20\end{array}$ & $\begin{array}{c}2,810 \pm 559 \\
744 \pm 142 \\
163 \pm 24 \\
47 \pm 11\end{array}$ & $\begin{array}{c}4,634 \pm 702^{*} \\
1,104 \pm 173^{*} \\
266 \pm 47^{*} \\
106 \pm 15^{*}\end{array}$ & $\begin{array}{c}7,717 \pm 824 \\
1,443 \pm 124 \\
525 \pm 71 \\
131 \pm 11\end{array}$ & $\begin{array}{c}5,940 \pm 608^{*} \\
1,160 \pm 86 \\
447 \pm 38 \\
103 \pm 11\end{array}$ & $\begin{array}{c}7,558 \pm 704 \\
1,434 \pm 121 \\
483 \pm 33 \\
114 \pm 11\end{array}$ \\
\hline $\begin{array}{l}\text { 5-HT } \\
\text { 5-HIAA }\end{array}$ & $\begin{array}{l}705 \pm 31 \\
296 \pm 47\end{array}$ & $\begin{array}{l}664 \pm 50 \\
347 \pm 27\end{array}$ & $\begin{array}{c}1,049 \pm 174 \dagger \\
482 \pm 57 \dagger\end{array}$ & $\begin{array}{l}236 \pm 31 \\
226 \pm 27\end{array}$ & $\begin{array}{l}205 \pm 35 \\
224 \pm 33\end{array}$ & $\begin{array}{l}221 \pm 36 \\
238 \pm 31\end{array}$ \\
\hline NA & $966 \pm 115$ & $1,100 \pm 195$ & $1,195 \pm 212$ & $268 \pm 25$ & $347 \pm 23^{*}$ & $347 \pm 15^{*}$ \\
\hline
\end{tabular}

Note-Values are means (ng/g tissue), with standard errors. DA $=$ dopamine. DOPAC $=$ dihydroxyphenylacetic acid. HVA = homovanillic acid. 3-MT = 3-methoxytyramine. 5-HT = 5-hydroxytryptamine. 5-HIAA $=5$-hydroxyindoleacetic acid. NA $=$ noradrenaline. ${ }^{*} p<.05,+p<.01$ relative to controls.

higher sucrose concentrations (Experiment 1, Weeks 6-7) revealed a bell-shaped concentration-intake curve, with maximal intake at the $2.1 \%$ or $7 \%$ concentrations (results not shown). Stressed animals consumed less of the $2.1 \%$ and $7 \%$ solutions $[9 \%$ decrease; $F(1,27)=5.9, p<.025$, at 7\%], but did not differ significantly at the two highest concentrations [ $5 \%$ decrease and $4 \%$ increase, respectively; $F(1,27)=1.4,1.0$, n.s.]. Meal-fed animals did not differ significantly from controls at any concentration of sucrose (Figure 1).

\section{Neurochemical Correlates}

Following 7 weeks of unpredictable mild stress (Experiment 1), levels of DA, and its metabolites dihydroxyphenylacetic acid (DOPAC), homovanillic acid (HVA), and 3-methoxytyramine (3-MT), were elevated by between $47 \%$ and $77 \%$ in the limbic forebrain of the stressed animals; no such changes were apparent in the caudate nucleus (Table 1). Levels of 5-hydroxytryptamine (5-HT) and its metabolite 5-hydroxyindoleacetic acid (5-HIAA) were also elevated in the limbic forebrain of the stressed animals. NA levels were unchanged in the limbic forebrain, but increased in the caudate nucleus; however, this change was seen also in the meal-fed controls, which did not show any alteration in sucrose consumption. The increased limbic forebrain levels of DA and 5-HT, and their metabolites, were replicated in Experiment 2, following only 3 weeks of stress (Figure 2). Again, no changes were apparent in the caudate nucleus $[\max F(1,36)=1.5$, n.s.]; neither were changes seen in the septal area [max $F(1,15)=1.3$, n.s.].

In Experiment 1, the increase in DA and its metabolites in limbic forebrain was accompanied by an $18 \%$ reduction in specific binding to D2 receptors, labeled with ${ }^{3} \mathrm{H}$-spiperone. There was also a smaller $(11 \%)$ but nonsignificant reduction in specific binding to D1 receptors, labeled with ${ }^{3} \mathrm{H}-\mathrm{SCH}-23390$ (Figure 3). The decrease in ${ }^{3} \mathrm{H}$-spiperone binding appeared to be related to a reduction in the number of binding sites, rather than a decrease in affinity. Neither the number of ${ }^{3} \mathrm{H}$-spiperone binding sites nor their affinity for ${ }^{3} \mathrm{H}$-spiperone was altered in the caudate nucleus (Table 2). There was no evidence of any

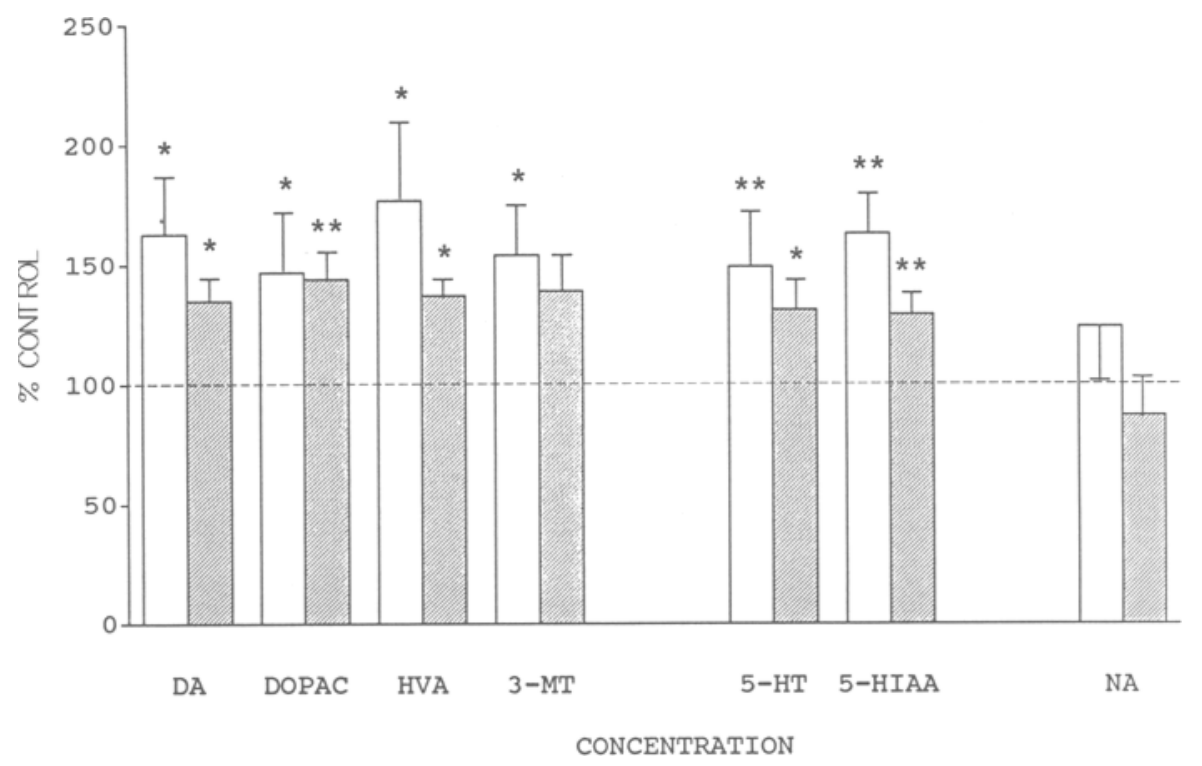

Figure 2. Effects of stress on transmitter and metabolite levels in limbic forebrain. Results are expressed as a proportion of nonstressed control values ( $M$ and $S E$ ). White bars, Experiment 1; hatched bars, Experiment 2. ${ }^{*} p<.05,{ }^{* *} p<.01$. 


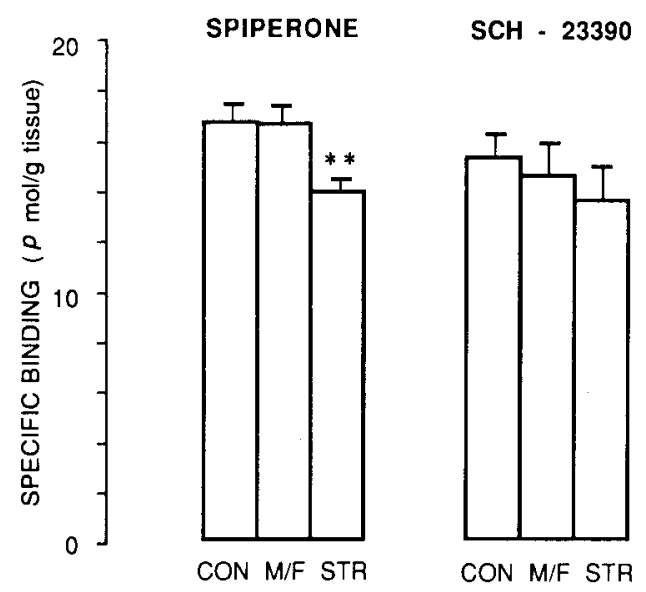

Figure 3. Specific binding of ${ }^{3} \mathrm{H}$-spiperone and ${ }^{3} \mathrm{H}-\mathrm{SCH}-23390$ in limbic forebrain samples, following 7 weeks of stress. CON, controls; $M / F$, meal-fed; STR, stress. Values are means $( \pm S E) .{ }^{* *} p<.01$.

difference in D2 agonist affinity between the three groups (results not shown). Unlike the transmitter/metabolite changes (see above), the decrease in D2 receptor binding was not replicated in Experiment 2: Specific binding of ${ }^{3} \mathrm{H}$-spiperone and ${ }^{3} \mathrm{H}-\mathrm{SCH}-23390$ in stressed animals was $96 \%$ and $99 \%$ of control values, respectively $[F(1,14)=$ 0.1 and 0.0 , n.s.].

\section{DISCUSSION}

These experiments confirm our earlier reports that chronic mild unpredictable stress drastically reduces the consumption of weak sucrose solutions (Muscat et al., 1990; Muscat et al., 1988; Sampson et al., in press; Willner et al., 1987). This is a very robust effect, which persists for at least 2 weeks following termination of the stress regime (Muscat et al., 1988). The decreased consumption of weak solutions is compatible with a decrease in the efficacy of the sucrose reward. This interpretation is supported by the observation that stress also reduces the rewarding efficacy of food, sucrose solutions, or amphetamine in the place preference paradigm (Willner, Muscat, et al., 1991; Willner, Sampson, Papp, Phillips, \& Muscat, in press). It is clear from the absence of differences between controls and meal-fed animals that the small weight loss in the stressed animals is not responsible for their behavioral and neurochemical abnormalities.

Consumption of very sweet solutions (14\% and $34 \%$ ) was normal in stressed animals; we have confirmed that

Table 2

Scatchard Analysis of ${ }^{3} \mathbf{H}$-Spiperone Binding

\begin{tabular}{lccccc}
\hline & \multicolumn{2}{c}{ Limbic Forebrain } & & \multicolumn{2}{c}{ Caudate Nucleus } \\
\cline { 2 - 3 } \cline { 6 - 6 } & B max & $\mathbf{K}_{\mathbf{D}}$ & & B max & $\mathbf{K}_{\mathbf{D}}$ \\
\hline Control & 18.0 & $\mathbf{0 . 2 1}$ & & 33.0 & $\mathbf{0 . 1 1}$ \\
Meal-fed & 17.6 & 0.19 & & 33.5 & 0.12 \\
Stress & 14.7 & 0.16 & & 31.7 & 0.11 \\
\hline
\end{tabular}

Note-B max is in $\mathrm{pmol} / \mathrm{g}, \mathrm{K}_{\mathrm{D}}$ in $\mathrm{nmol}$. stress does not impair the consumption of very sweet solutions in two further experiments (Muscat \& Willner, unpublished data; Willner, Sampson, et al., in press). The failure of stress to reduce the consumption of very sweet solutions at first sight appears to argue against an anhedonic effect of stress. However, the positive relationship between responding and reward value only holds over a limited range of low reward values; at higher values, the reward function saturates (Bailey, Hsiao, \& King, 1986; Hodos \& Valenstein, 1962; Miliaressis \& Malette, 1987; Waraczynski, Stellar, \& Gallistel, 1987). Consequently, when very sweet rewards are used, consumption does not provide a measure of their reward value (Phillips, Blaha, \& Fibiger, 1989; Phillips, Muscat, \& Willner, 1989; Willner, Phillips, \& Muscat, 1991). These effects of chronic mild stress appear highly comparable to those of DA receptor antagonists, which also suppress sucrose consumption selectively at low concentrations (Muscat \& Willner, 1989; Towell et al., 1987). Other similarities between the effects of chronic mild stress and DA antagonists include a decrease in the anorexic efficacy of apomorphine and amphetamine, a decrease in the rate of food consumption, and an increase in the consumption of a very sweet wet mash (Muscat, Sampson, Phillips, \& Willner, 1989; Muscat et al., 1988).

In both of the present experiments, chronic mild stress increased levels of DA, 5-HT, and their metabolites in the limbic forebrain. These changes were anatomically specific: No significant changes related to DA or 5-HT were observed in the caudate nucleus or septal area. Although stress did not alter the DA/metabolite ratio (i.e., all changes were of a comparable magnitude), the receptor changes observed in Experiment 1 are suggestive of an increase in the release of DA in the limbic forebrain (together with an increase in DA synthesis) in chronically stressed animals. In subsequent experiments, we have confirmed, using fast cyclic voltammetry, that chronic mild stress increases both the release of DA in response to electrical stimulation of the medial forebrain bundle, and the size of the releaseable pool of DA (Stamford et al., 1991). A chronic increase in the level of DA release would explain our earlier observation that chronically stressed animals are subsensitive to stimulation of presynaptic DA autoreceptors (Muscat et al., 1988); this effect was also observed in a voltammetric study in brain slices taken from the nucleus accumbens (Stamford et al., 1991).

It is necessary to reconcile the neurochemical evidence that DA release is increased by chronic mild stress with the functional evidence that the effects of chronic mild stress resemble those of DA antagonist drugs. Specific binding to D2 receptors was decreased in Experiment 1 (though not in Experiment 2), which might suggest that increased DA release is offset by a decrease in postsynaptic receptor function. However, it is clear from the negative results of Experiment 2 that there is no simple correlation between D2 receptor number and behavioral subsensitivity to reward. Furthermore, decreased sensi- 
tivity to reward has been observed following a single session of exposure to inescapable footshock, indicating that postsynaptic receptor changes are not required for this effect (Zacharko \& Anisman, 1991; Zacharko et al., 1984; Zacharko et al., 1983).

Acute exposure to stress is known to increase the turnover of DA in the mesolimbic system (Blanc et al., 1980; Dunn, 1988; Kalivas \& Abhold, 1987; Thierry, Tassin, Blanc, \& Glowinski, 1976). The present findings indicate that this effect does not undergo tolerance when animals are exposed chronically to mild stress, probably owing to the unpredictability of the chronic mild stress regimen (Kant et al., 1983); on the contrary, it appears that increased release of DA is matched by an increase in synthesis. Because the baseline of presynaptic DA activity is higher, stronger levels of stimulation may be necessary to elicit further increases. This may provide an explanation of the paradox that chronically stressed animals are subsensitive to reward, since stimuli that normally would activate the mesolimbic system may now be prevented from doing so.

A tonic increase in 5-HT release would also tend to depress sucrose intake (Blundell, 1986; Garattini, Mennini, Bendotti, Invernizzi, \& Samanin, 1986; Muscat et al., in press). However, indirect evidence suggests that 5-HT receptors may be desensitized by chronic exposure to mild unpredictable stress, since stressed animals are subsensitive to both the anorectic action of fenfluramine and the orectic action of 8-hydroxy-DPAT (Muscat et al., 1989). A decrease in 5-HT receptor function would tend to offset the effects of an increase in 5-HT release. Nevertheless, the potential involvement of 5-HT in mediating the effects of chronic mild stress, as well as the role of DA/5-HT interactions within the nucleus accumbens, merits investigation.

Stress is known to play a role in the etiology of depression (Anisman \& Zacharko, 1982; Brown \& Harris, 1988; Kanner, Coyne, Schaefer, \& Lazarus, 1981; Lloyd, 1980a, $1980 \mathrm{~b}$ ), and the major subtype of severe depression, melancholia, is characterized by anhedonia, an inability to experience pleasure, which may be homologous to a reduced sensitivity to reward (American Psychiatric Association, 1980; Klein, 1974; Nelson \& Charney, 1981; Willner, Sampson, et al., in press). The reduction of sucrose consumption by chronic mild unpredictable stress may be reversed by chronic treatment with antidepressant drugs (Muscat et al., 1990; Muscat et al., 1988; Sampson et al., in press; Willner et al., 1987), and this effect is selectively reversed by low doses of DA antagonists (Muscat et al., 1990; Sampson et al., in press). Thus, the present findings may be of importance for understanding the mechanism of melancholia.

\section{REFERENCES}

American Psychintric Association (1980). DSM III-Diagnostic and statistical manual of psychiatric disorders. Washington, DC: Author. Anderson, D. C., Cole, J., McV Augh, W. (1968). Variations in unsignalled inescapable preshock as determinants of responses to punishment. Joumal of Comparative \& Physiological Psychology, 65 (Monograph Suppl.), 1-17.

Anisman, H., ZaChaRko, R. M. (1982). Depression: The predisposing influence of stress. Behavioral \& Brain Sciences, 5, 89-137.

Bailey, C. S., Hsiao, S., King, J. E. (1986). Hedonic reactivity to sucrose in rats: Modification by pimozide. Physiology \& Behavior. 38, 447-452.

Blanc, G., Herve, D., Simon, H., Lisoprawsi, A., Glowinski, J., \& TAssin, J. P. (1980). Response to stress of mesocortical frontal dopaminergic neurons in rats after long-term isolation. Nature, 284, 265-276

BLUNDELL, J. E. (1986). Serotonin manipulations and the structure of feeding behaviour. Appetite, 7 (Suppl.), 39-56.

Brown, G. W., Harris, T. (Eds.) (1988). Life events and illness. New York: Guilford Press.

De Cola, J. P., Rosellini, R. A., Warren, D. A. (1988). A dissociation of the effects of control and prediction. Leaming \& Motivation, 19, 269-282.

DUNN, A. J. (1988). Stress-related activation of cerebral dopaminergic systems. Annals of the New York Academy of Sciences, 537, 188-205.

Garattini, S., Mennini, T., Bendotti, C., Invernizzi, R., \& SAMANIN, R. (1986). Neurochemical mechanism of action of drugs which modify feeding via the serotonergic system. Appetite, 7 (Suppl.), 15-38.

Hefrner, T. G., Hartman, J. A., Seiden, L. S. (1980). Feeding increases dopamine metabolism in the rat brain. Science, 208, $1168-1170$.

Hernandez, L., \& Hoebel, B. G. (1988). Food reward and cocaine increase extracellular dopamine in the nucleus accumbens as measured by microdialysis. Life Sciences, 42, 1705-1712.

Hodos, W., \& Valenstein, E. S. (1962). An evaluation of response rate as a measure of rewarding intracranial stimulation. Journal of Comparative \& Physiological Psychology, 55, 80-84.

Hoebel, B. G., Hernandez, L., Mclean, S., Stanley, B. G., Aulissi, E. F., Gumcher, P., \& Margolin, D. (1981). In B. G. Hoebel \& D. Novin (Eds.), The neural basis of feeding and reward (pp. 465-478). Brunswick, ME: Haer Institute.

Kalivas, P. W., ABhold, R. (1987). Enkephalin release into the ventral tegmental area in response to stress: Modulation of mesocorticolimbic dopamine. Brain Research, 414, 339-348.

Kanner, A. D., Coyne, J. C., Schaefer, C., Lazarus, R. S (1981). Comparison of two modes of stress measurement: Daily hassles and uplifts versus major life events. Journal of Behavioral Medicine, 4, 1-39.

Kant, G. J., Eggleston, T., Landman-Rogerts, L., Kenion, C. C. Driver, G. C., \& MeYerhoff, J. L. (1983). Habituation to repeated stress is stressor specific. Pharmacology, Biochemistry \& Behavior, 22, 631-634.

KATZ, R. J. (1982). Animal model of depression: Pharmacological sensitivity of a hedonic deficit. Pharmacology, Biochemistry \& Behavior, 16, 965-968.

KLEIN, D. F. (1974). Endogenomorphic depression: A conceptual and terminological revision. Archives of General Psychiatry, 31, 447-454.

Kumex, V., \& MN, J. (1990). Repeated administration of antidepressant drugs enhanced agonist affinity for mesolimbic D-2 receptors. Journal of Pharmacy \& Pharmacology, 41, 555-558.

KuimeK, V., Nielsen, M. (1987). Chronic treatment with antidepressants decreases the number of [3H]SCH 23390 binding sites in the rat striatum and limbic system. European Joumal of Pharmacology, 139, 163-169.

LLoyd, C. (1980a). Life events and depressive disorders reviewed: 1. Events as predisposing factors. Archives of General Psychiarry, 37, 529-535.

LLoYd, C. (1980b). Life events and depressive disorders reviewed: 2. Events as precipitating factors. Archives of General Psychiatry, 37, 541-548.

Miliaressis, E., Malette, J. (1987). Summation and saturation properties in the rewarding effect of brain stimulation. Physiology \& Behavior, 41, 595-604.

Muscat, R., Sampson, D., Phillips, G., \& Willner, P. (1989). 
Animal model of depression: Indirect evidence of dopamine dysfunction. Behavioural Pharmacology, 1 (Suppl. 1), 55.

Muscat, R., Sampson, D., \& Willner, P. (1990). Dopaminergic mechanism of imipramine action in an animal model of depression. Biological Psychiatry, 28, 223-230.

Muscat, R., Towell, A., \& Willner, P. (1988). Changes in dopamine autoreceptor sensitivity in an animal model of depression. Psychopharmacology, 94, 545-550.

MUSCAT, R., WILLNER, P. (1989). Effects of selective dopamine receptor antagonists on sucrose consumption and preference. Psychopharmacology, 99, 98-102.

Nelson, J. C., Charney, D. S. (1981). The symptoms of major depression. American Journal of Psychiatry, 138, 1-13.

Phillips, A. G., Blaha, C. D., \& Fibiger, H. C. (1989). Neurochemical correlates of brain-stimulation reward measured by ex vivo and in vivo analyses. Neuroscience \& Biobehavioral Reviews, 13, 99-104.

Phillips, G., Muscat, R., \& Willner, P. (1989). Dopamine blockade can increase rewarded behaviour: $I$. Consumption of very sweet solutions. Behavioural Pharmacology, 1 (Suppl. 1), 14.

RoselLINI, R. A. (1978). Inescapable shock interferes with the acquisition of an appetitive operant. Animal Learning \& Behavior, 6, 155-159.

Rosellini, R. A., \& DE Cola, J. P. (1981). Inescapable shock interferes with the acquisition of a low-activity response in an appetitive context. Animal Learning \& Behavior, 9, 487-490.

Rosellini, R. A., De Cola, J. P., Plonsky, M., Warren, D. A., \& Stillman, A. J. (1984). Uncontrollable shock proactively increases sensitivity to response-reinforcer independence in rats. Journal of $E x$ perimental Psychology: Animal Behavior Processes, 10, 346-359.

SAmpson, D., Muscat, R. \& Willner, P. (in press). Reversal of antidepressant action by dopamine antagonists in an animal model of depression. Psychopharmacology.

Stamford, J. A., Muscat, R., O'Connor, J. J., Patel, J., Trout, S. J. Wieczorek, W. J., Kruk, Z. L., Willner, P. (1991). Voltammetric evidence that subsensitivity to reward following chronic mild stress is associated with increased release of mesolimbic dopamine. Manuscript submitted for publication.

Thierry, A. M., Tassin, J. P., Blanc, G., \& Glowinski, J. (1976). Selective activation of the mesocortical dopamine system by stress. Nature, 263, 242-244.

Towell, A., Muscat, R., \& Willner, P. (1987). Effects of pimozide on sucrose consumption and preference. Psychopharmacology, 92 , 262-264.

Waraczynski, M., Stellar, J. R., \& Gallistel, C. R. (1987). Reward saturation in medial forebrain bundle self-stimulation. Physiology \& Behavior, 41, 585-593.

Willner, P., Muscat, R., PAPp, M., SAmpson, D. (1991). Dopamine, depression and antidepressant drugs. In P. Willner \& J. ScheelKruger (Eds.), The mesolimbic dopamine system: From motivation to action. Chichester, U.K.: Wiley.

Willner, P., Phillips, G., \& Muscat, R. (1991). Suppression of rewarded behaviour by neuroleptic drugs: Can't or won't, and why? In P. Willner \& J. Scheel-Krüger (Eds.), The mesolimbic dopamine system: From motivation to action (pp. 249-270). Chichester, U.K.: Wiley.

Willner, P., Sampson, D., Papp, M., Phillips, G., \& Muscat, R. (in press). Animal models of anhedonia. In P. Simon, P. Soubrie, \& D. Widlocher (Eds.), Animal models of psychiatric disorders (Vol. 3). Basel: Karger.

Willner, P., Towell, A., Sampson, D., Sophokleous, S., \& MUSCAT, R. (1987). Reduction of sucrose preference by chronic mild stress and its restoration by a tricyclic antidepressant. Psychopharmacology, 93, 358-364.

WISE, R. A. (1982). Neuroleptics and operant behavior: The anhedonia hypothesis. Behavioral \& Brain Sciences, 5, 39-87.

WISE, R. A., \& BozARTH, M. A. (1984). Brain reward circuitry: Four elements "wired" in apparent series. Brain Research Bulletin, 12, 203-208.

ZaChaRko, R. M., \& ANISMAN, H. (1991). Stressor-provoked alterations of intracranial self-stimulation in the mesocorticolimbic dopamine system: An animal model of depression. In P. Willner \& J. Scheel-Krüger (Eds.), The mesolimbic dopamine system: From motivation to action (pp. 409-440). Chichester, U.K.: Wiley.

Zacharko, R. M., Bowers, W. J., Anisman, H. (1984). Responding for brain stimulation: Stress and desmethylimipramine. Progress in Neuro-Psychopharmacology \& Biological Psychiatry, 8, 601-606.

ZaCharko, R. M., Bowers, W. J., Kokkinidis, L., \& ANisman, H. (1983). Region specific reductions of intracranial self-stimulation after uncontrollable stress: Possible effects on reward processes. Behavioral Brain Research, 9, 129-141.

(Manuscript received April 3, 1990; revision accepted for publication July 23,1990 .) 